Ciência e Natura, Santa Maria, v. 37 n. 3 set-dez. 2015, p.311-328

Revista do Centro de Ciências Naturais e Exatas - UFSM

ISSN impressa: 0100-8307 ISSN on-line: 2179-460X

\title{
ciênciaenatura
}

\section{A Geomorfologia do município de Arroio do Padre - RS e as suas relações com as Alterações Geomorfológicas da Enxurrada de 15 de novembro de 2010.}

\author{
Geomorphology of the municipality of Arroio do Padre (Rio Grande do Sul State) and its \\ relations with the geomorphological changes due to November 15th 2010 Flash-flood
}

\author{
Mauricio Meurer, Cláudia Werner Flach \\ Universidade Federal de Pelotas, RS, Brasil.
}

\begin{abstract}
Resumo
O Brasil é um dos dez países mais afetados por desastres naturais no mundo, predominando a ocorrência de eventos de origem hidrológica. No Estado do Rio Grande do Sul, o município de Arroio do Padre foi atingido por três episódios pluviométricos de grande intensidade entre 2009 e 2011. O presente trabalho tem por objetivos elaborar uma cartografia geomorfológica para o município de Arroio do Padre - RS com base em trabalhos anteriores, em fotografias aéreas e informações de campo, identificando as alterações geomorfológicas decorrentes da enxurrada de 15 de novembro de 2010 e levantando junto a alguns moradores das áreas mais atingidas sua percepção sobre este evento. A realização deste trabalho mostrou que a enxurrada que ocorreu em Arroio do Padre foi causada por um grande volume precipitado em um curto intervalo de tempo, mas as fortes declividades e os solos com limitações à infiltração desempenharam um papel importante para o desencadeamento dos movimentos de massa. Tanto o mapa geomorfológico como o mapeamento das consequências da enxurrada mostraram que existem setores preferenciais de maior risco à ocorrência de processos erosivos, de movimentos de massa, de inundação e de processos deposicionais, o que abre caminho para um futuro estudo de vulnerabilidade.
\end{abstract}

Palavras-chave: Arroio do Padre, enxurrada, cartografia geomorfológica.

\begin{abstract}
Brazil is one of the ten countries most touched by natural disasters in the world, being mainly affected by events of hydrological origin. In the state of Rio Grande do Sul, the municipality of Arroio do Padre was hit by three episodes of high intensity rainfall between the years of 2009 to 2011 This paper aims to develop a geomorphological mapping for the municipality of Arroio do Padre, identifying the geomorphological changes resulting from the flash-flood of November 15th 2010, and identifying with some residents of the hardest hit areas their perception about this event. This research showed that the flash-flood which occurred in Arroio do Padre was caused by a large rainfall volume in a short time, but the steepest slopes and soils with limitations to infiltration played an important role in the triggering of the mass movements. Both geomorphological map as the mapping of the consequences of the flash-flood showed that there are preferential areas of greatest risk to the occurrence of erosion, mass movements, flooding and depositional processes, paving the way for future studies of vulnerability.
\end{abstract}

Keywords: Arroio do Padre, flash-floods, geomorphological mapping. 


\section{Introdução}

$\mathrm{O}$ crescente número no registro de desastres naturais torna-se cada vez mais preocupante, e os constantes prejuízos econômicos, sociais e ambientais resultantes destes eventos demandam muitos gastos na recuperação das áreas atingidas. Segundo GuhaSapir et al (2012), o Brasil é um dos dez países mais afetados por desastres naturais no mundo, predominando a ocorrência de eventos de origem hidrológica, ou seja, as inundações, as enxurradas, os alagamentos, e os movimentos de massa desencadeados por eventos pluviométricos extremos e prolongados (KOBYIAMA et al, 2006; TOMINAGA, 2009; SAUSEN et al, 2012; ROBAINA e OLIVEIRA, 2013). No Estado do Rio Grande do Sul, estudos realizados por Menezes e Sccoti (2013) indicam que, entre 1980 e 2010, foram registradas 1.742 enxurradas, ocorrendo predominantemente nos meses de novembro, dezembro, janeiro e maio. Estes meses marcam o período de transição de massas de ar e, consequentemente, são muito favoráveis à ocorrência de precipitações mais intensas.

Na região sul do Rio Grande do Sul, o município de Arroio do Padre (Fig. 1) tornou-se um exemplo emblemático na questão dos desastres naturais. Em um período de três anos, este município foi atingido pelo menos três vezes por episódios pluviométricos de grande intensidade, com grandes volumes precipitados em curtos intervalos de tempo (as chuvas de 28 29 Janeiro de $2009^{1}$, as chuvas de 15 novembro de 2010 e as chuvas de 09 - 11 de março de 2011). Em ao menos dois destes eventos, a Prefeitura Municipal de Arroio do Padre decretou situação de emergência (após a enxurrada de novembro de 2010, e após as chuvas intensas de março de 2011).

No episódio mais marcante, registrado em 15 de novembro de 2010, o município de Arroio do Padre foi atingido por um volume de precipitação superior a $320 \mathrm{~mm}$ em um período aproximado de 3 horas (EMATER, 2010), com a ocorrência de granizo. Os prejuízos ocasionados pela chuva, pelo granizo e pela enxurrada contabilizaram um valor superior a R \$ 7 milhões (EMATER, 2010), gerando grandes transtornos para a população.
Durante este evento, houve o registro de danos consideráveis às áreas de lavoura, às pontes, às estradas rurais, à infra-estrutura de drenagem, e ao patrimônio privado, além da intensificação e do desencadeamento de uma série de processos de transformação do relevo e da rede hidrográfica.

Por ser um município relativamente novo, Arroio do Padre ainda carece de informações básicas sobre o seu território, o que torna a tarefa de planejamento e ordenamento territorial um grande desafio para os gestores do respectivo município. Arroio do Padre precisa dispor de instrumentos que orientem a ocupação do espaço, e que sirvam de base para a elaboração de novos trabalhos, que alertem a população para os riscos potenciais aos quais estão expostos.

A Cartografia Geomorfológica tem se mostrado uma valiosa ferramenta nos processos de gestão do território e de diagnóstico dos riscos potenciais. Conforme DIAS et. al (2009) "os mapeamentos geomorfológicos são um importante documento para o planejamento e gestão do território, pois permitem definir as potencialidades e limitações nas áreas em estudo frente aos diferentes tipos de uso da terra". Sendo a Geomorfologia um dos fatores de controle da paisagem (junto com outros fatores tais como a Geologia, o Clima, a Vegetação, as Atividades Antrópicas, entre outros), é fundamental que possamos dispor de informações confiáveis e precisas a este respeito, que orientem nossas práticas e minimizem nossos riscos.

No que se refere a riscos, a Cartografia Geomorfológica tem uma relação direta com esta temática. Inúmeros projetos de prevenção e minimização de riscos, tanto em áreas urbanas como em áreas rurais, têm como ponto de partida a elaboração de uma Cartografia Geomorfológica, como é o caso dos trabalhos realizados por Casseti e Nascimento (1991), Lambert (1996), Santos e Sobreira (2006), entre outros. Considerando-se esta aplicabilidade da Cartografia Geomorfológica na prevenção de riscos, surgiu esta proposta de elaboração de um mapeamento geomorfológico para o município de Arroio do Padre, e um estudo das consequências das enxurradas de 15 de novembro de 2010.

1 Durante este episódio, foram registrados, na Estação Experimental da Cascata, localizada cerca de $23 \mathrm{~km}$ ao sul de Arroio do Padre, $586 \mathrm{~mm}$ de precipitação no intervalo de $24 \mathrm{~h}$. 


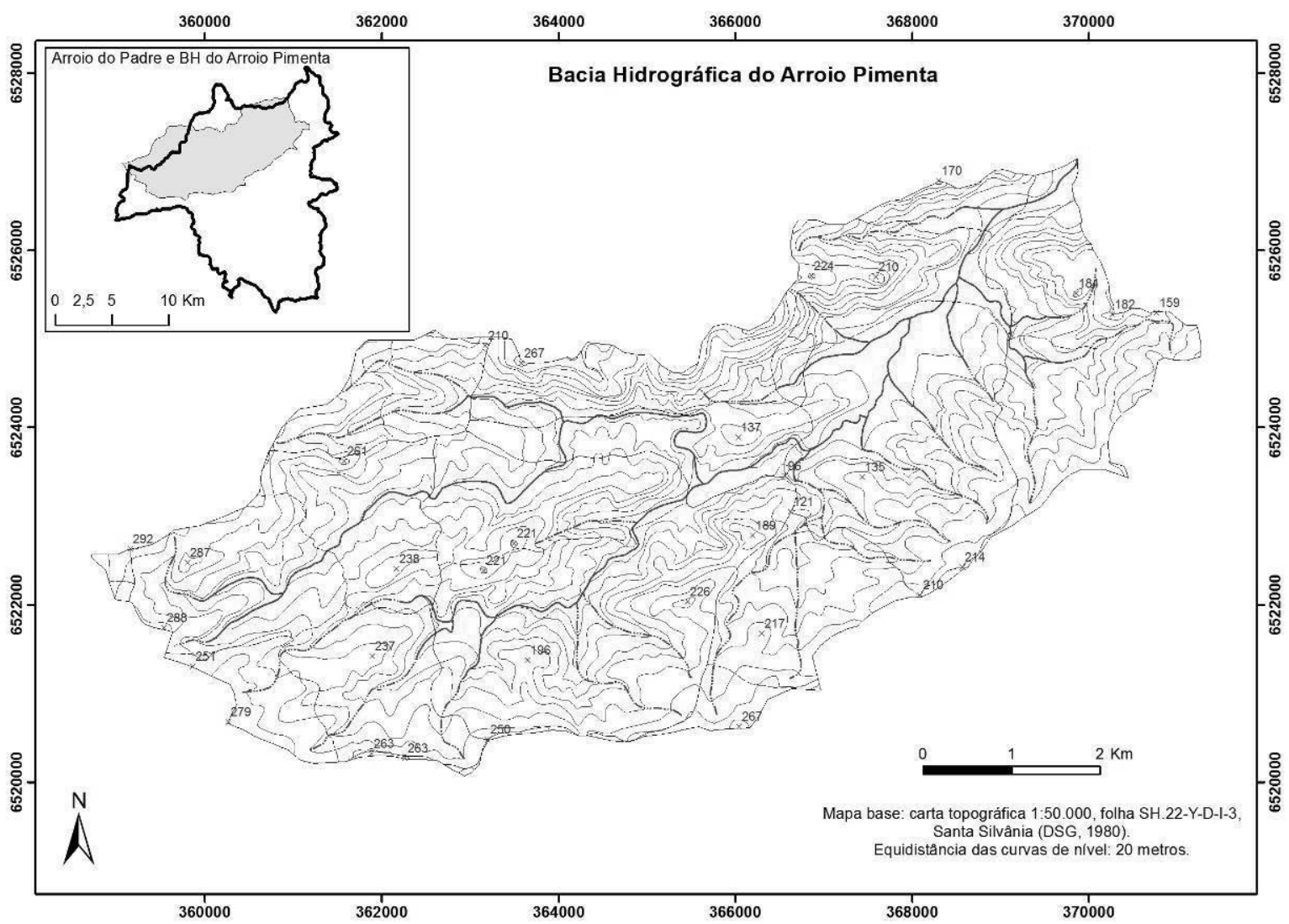

Figura 1. Município de Arroio do Padre e localização da Bacia Hidrográfica do Arroio Pimenta.

\section{2 Área de Estudo}

O município de Arroio do Padre (Fig. 1) pertence à mesorregião Sudeste-riograndense $\mathrm{e}$ faz parte da Microrregião de Pelotas. Com uma área de 124,317 km², Arroio do Padre possui 2.730 habitantes, sendo 454 habitantes na área urbana e 2.276 habitantes na área rural (IBGE, 2013).

Do ponto de vista geológico, o município assenta-se sobre duas suítes intrusivas, a suíte Dom Feliciano $(572 \pm 10 \mathrm{Ma})$, formada por rochas graníticas (sienogranitos e monzogranitos) alinhadas a NE-SW, e a suíte Pinheiro Machado $(609 \pm 17 \mathrm{Ma}$ a $781 \pm 5 \mathrm{Ma})$, também formada por rochas graníticas-gnáissicas, com metamorfismo importante (CPRM, 2000). O controle estrutural das rochas subjacentes é perceptível através do alinhamento dos vales e de elementos da rede de drenagem, orientados nos sentidos preferenciais E-W e NE-SW. Apesar de não constar em nenhum mapeamento geológico, é importante destacar a existência de depósitos quaternários inconsolidados, não identificados, que recobrem as encostas e os fundos de vale, sendo frequentemente retrabalhados pelos processos morfogenéticos e pela rede de drenagem.

No que tange a pedologia, predominam no município os Argissolos Vermelho Amarelo Distróficos e os Neossolos Litólicos Distróficos. Ambos solos são de baixa fertilidade e apresentam muitas limitações quanto à infiltração, favorecendo o escoamento superficial e o desencadeamento de processos erosivos. (OLIVEIRA, JACOMINE e CAMARGO, 1992; IBGE, 2003b). Conforme o Plano Ambiental Municipal de Arroio do Padre (2008), nas áreas mais elevadas do embasamento cristalino, onde predominam os solos rasos e os afloramentos rochosos, não é recomendado o uso agrícola. Nas áreas menos íngremes de relevo ondulado, os solos podem ser utilizados com culturas anuais, desde que os fortes efeitos da erosão laminar sejam controlados. $\mathrm{Na}$ transição para a planície costeira, o relevo ondulado e o solo apresentam alta suscetibilidade à erosão, entretanto são 
utilizados para a policultura em pequenas propriedades.

Por ser um município majoritariamente rural, o uso do solo é caracterizado pelo predomínio de culturas cíclicas, como o milho, o feijão, a batata, entre outros. Estes cultivos são realizados principalmente em minifúndios. Nos últimos anos, porém, há uma participação significativa do cultivo de fumo, sendo este atualmente o cultivo de maior representatividade (PMAP, 2008).

\section{Objetivos}

Considerando toda a problemática enfrentada pelo município de Arroio do Padre com a ocorrência das enxurradas, o presente trabalho teve por objetivos: a) Elaborar um mapa geomorfológico para o município de Arroio do Padre - RS na escala $1 / 50.000$; b) Identificar em campo as alterações geomorfológicas decorrentes da enxurrada de 15 de novembro de 2010; c) Levantar junto a alguns moradores das áreas mais atingidas pela enxurrada qual a sua percepção sobre os eventos extremos e sobre os acontecimentos de 15 de novembro de 2010.

\section{Metodologia}

\subsection{Cartografia Geomorfológica}

Antecedendo a realização desta pesquisa, duas propostas de cartografia geomorfológica estavam disponíveis para o município de Arroio do Padre. A primeira refere-se ao mapa Geomorfológico publicado pelo IBGE (2003a) na escala 1/250.000. Esta carta foi originalmente elaborada pelo projeto RADAMBRASIL, no período de maio de 1980 a agosto de 1982, com base em interpretações de mosaicos semicontrolados de imagens de radar e apoio de campo, na escala 1/250.000. Além desta carta, o município ainda dispunha de uma descrição de sua geomorfologia no Plano Ambiental do Município de Arroio do Padre (PMAP, 2008). Neste plano, no item referente à Geomorfologia do município, as informações apresentadas descrevem a Geomorfologia utilizando os trabalhos do IBGE (1986) e de Tagliani (2002). Apesar disto, o referido plano não apresenta nenhum tipo de mapeamento geomorfológico; apenas um mapa intitulado geológico geomorfológico, mas que contempla basicamente informações da geologia (grandes províncias geológicas onde assenta-se $\mathrm{o}$ município).

Para a elaboração da Cartografia Geomorfológica do município de Arroio do Padre, foi elaborado um esquema metodológico (Fig. 2) que mesclou informações das cartografias geomorfológicas já existentes com informações inéditas extraídas de fotografias aéreas, imagens de satélite, de observações de campo e trabalho de gabinete. $\mathrm{O}$ esquema metodológico elaborado buscou se adequar a metodologia de cartografia geomorfológica proposta pelo IBGE (2009), porém com algumas modificações. Desta metodologia, foram retidos os níveis taxonômicos, a divisão do $4^{\circ}$ nível taxonômico em modelados de dissecação (representados pela letra D) e modelados de Acumulação (representados pela letra A), e a maior parte das simbologias (salvo algumas adaptações para simbologias não previstas na metodologia original).

Em uma primeira etapa, foi realizada a construção de uma base cartográfica de trabalho. Esta base foi elaborada através da compilação de informações provenientes de duas fontes distintas: 1) o mapa do Cadastro Imobiliário de Arroio do Padre, escala 1/25.000, fornecido pela Prefeitura Municipal de Arroio do Padre em um arquivo vetorial digital, e; 2 ) a Base cartográfica vetorial contínua do Rio Grande do Sul (HASENACK \& WEBER, 2010), escala 1/50.000. Do Cadastro Imobiliário de Arroio do Padre foram selecionados os planos de informação do Limite Municipal, da Hidrografia (intermitente e perene), e do Sistema Viário. Da Base vetorial do RS foram selecionados os planos de informação das Curvas de Nível (equidistância de $20 \mathrm{~m}$ ) e dos Pontos Cotados. A reunião destas informações em um único arquivo vetorial georreferenciado deu origem à Base Cartográfica de Trabalho.

A partir da base cartográfica gerada, foram elaborados um mapa hipsométrico, fatiado em intervalos de $50 \mathrm{~m}$, e um mapa de declividades, de acordo com as classes de declividade propostas por ROSS (1992). O mapa hipsométrico foi utilizado para auxiliar na 
localização e detalhamento dos limites entre as unidades geomorfológicas, na identificação de vales e sulcos estruturais, e na identificação das principais linhas de crista que cortam o município de Arroio do Padre. O mapa de

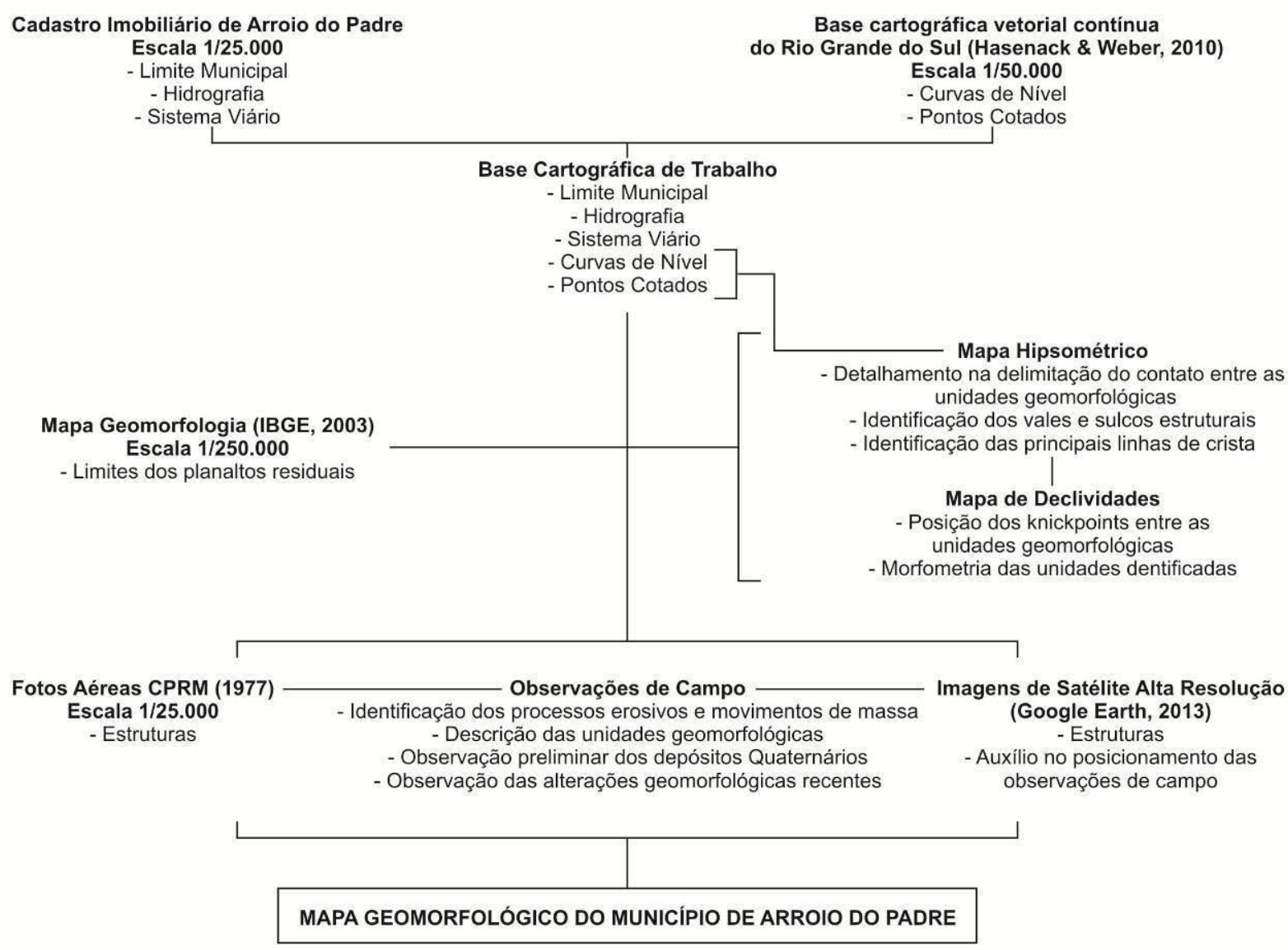

Figura 2. Esquema metodológico utilizado para a elaboração do mapa geomorfológico do município de Arroio do Padre.

importante para outras interpretações relacionadas à ocorrência das enxurradas e dos processos morfogenéticos (erosão, movimentos de massa).

$\mathrm{Na}$ etapa seguinte, foi realizada a sobreposição das unidades geomorfológicas presentes no Mapa de Geomorfologia (IBGE, 2003a) sobre a Base Cartográfica de Trabalho. Por ter sido elaborado em escala mais generalizada, os limites das unidades geomorfológicas não apresentaram boa correspondência com a topografia da Base Cartográfica de Trabalho. Assim sendo, o detalhamento destes limites foi realizado com o auxílio dos mapas hipsométrico e de declividades, levando-se em consideração as mudanças de declividade e de altitude, e declividades, por sua vez, auxiliou na localização dos knickpoints que separam as unidades geomorfológicas identificadas e para a caracterização da morfometria (declividade) destas unidades. Este mapa ainda foi 
Geomorfológico do Município de Arroio do Padre (Fig.5).

\subsection{Levantamento das Consequências da Enxurrada}

O levantamento das consequências das enxurradas foi realizado em três etapas. $\mathrm{Na}$ primeira etapa, foi feita uma conversa informal com os técnicos da Prefeitura Municipal de Arroio do Padre e da EMATER sobre as enxurradas e suas consequências. Nesta ocasião, foram obtidos junto aos técnicos da Prefeitura Municipal de Arroio do Padre e da EMATER cerca de 500 registros fotográficos feitos por estes técnicos nos dias subseqüentes a enxurrada. Estas fotografias serviram para elaborar um primeiro repertório das consequências da enxurrada, e também para selecionar alguns locais a serem posteriormente visitados em campo.

Em uma segunda etapa, buscou-se observar sobre as imagens de satélite de alta resolução a presença de feições que pudessem estar associadas às enxurradas, tais como cicatrizes de movimentos de massa, feições erosivas lineares, feições deposicionais, e alterações da rede de drenagem. Todas as áreas identificadas através das imagens foram posteriormente verificadas em campo.

Em uma terceira etapa, foram realizadas entrevistas com a aplicação de um breve questionário com os moradores das áreas mais atingidas do município. Nestas entrevistas, procurou-se levantar quais as consequências da enxurrada observadas pelos moradores em suas propriedades e áreas próximas.

\subsection{Levantamento das Percepções dos Moradores}

No intuito de conhecer a percepção dos moradores sobre as enxurradas, o questionário aplicado na etapa de campo trazia uma série de questões referentes a reconstituição do evento (hora de início e término, estimativa do volume precipitado, etc.), sobre a percepção do evento (suas causas prováveis, sobre a possibilidade de um evento deste porte se repetir, etc.), e sobre risco, processos erosivos e o manejo da propriedade (se consideram estar em uma área de risco, se utilizam alguma técnica preventiva de controle a erosão).

\section{Resultados e Discussões}

\subsection{Cartografia Geomorfológica}

A elaboração do mapa geomorfológico do município de Arroio do Padre (Fig.5) aportou algumas modificações e contribuições em relação a estes trabalhos precedentes:

- Detalhamento dos limites entre as duas unidades de planalto - em relação aos mapas precedentes, o mapa proposto apresenta com maior detalhamento o limite de contato entre os Planaltos Residuais Canguçu - Caçapava do Sul e o Planalto Rebaixado Marginal;

- Inclusão da unidade da Planície AlúvioColuvionar - nas cartografias anteriores esta unidade não era representada no interior do município. A ocorrência da enxurrada de 15 de novembro de 2010 e as transformações observadas na paisagem de Arroio do Padre mostraram que estas áreas tem um comportamento diferenciado em relação às vertentes dos planaltos, de forma que a sua individualização como unidade geomorfológica é importante e necessária;

- Exclusão da unidade de Colúvios presente no mapa elaborado por Tagliani (2002) - segundo este autor, na porção sul do município existiriam depósitos de colúvios que fariam a transição para os Depósitos Continentais da Planície Costeira do Rio Grande do Sul. Opondo-se a isto, os mapas de geomorfologia do IBGE (2003a) e a carta geológica do CPRM (2000) indicam que estes depósitos estão situados bem mais distantes do município. Nas observações de campo, não foi possível confirmar a presença destes depósitos, de forma que optou-se por não representá-los. Fica a ressalva de que, o fato de não terem sido representados não exclui a possibilidade de existência dos mesmos;

- Detalhamento na descrição das unidades geomorfológicas e das feições estruturais - além do trabalho de mapeamento, as unidades geomorfológicas foram detalhadamente descritas no relatório final apresentado ao órgão de fomento desta pesquisa (MEURER, 2013). Esta descrição foi realizada levando em consideração as orientações da União 
Geográfica Internacional para que sejam observados os aspectos morfométricos, morfográficos, morfogenéticos e cronológicos. Incluiu-se também o detalhamento na descrição de algumas feições estruturais, tais como os vales estruturais assimétricos, as linhas de crista e as marcas de enrugamento;

- Identificação pontual dos processos morfogenéticos - Ausente em todas as cartografias precedentes, este é o primeiro trabalho a identificar e espacializar alguns dos processos morfogenéticos que ocorreram e ocorrem no município de Arroio do Padre, tais como as erosões lineares, os movimentos de massa, as incisões nas cabeceiras de drenagem, entre outros.

A seguir, são apresentadas as descrições das unidades geomorfológicas mapeadas.

\subsubsection{Planaltos Residuais Canguçu - Caçapava do Sul}

A unidade dos Planaltos Residuais Canguçu - Caçapava do Sul corresponde a uma porção mais elevada do Planalto Sul-Riograndense que se estende da porção mais central desta região geomorfológica até o município de Arroio do Padre.

No interior do município de Arroio do Padre esta unidade caracteriza-se pelos terrenos mais elevados, geralmente superiores a cota de $150 \mathrm{~m}$, que dominam a porção oeste do município.

Morfologicamente, estas áreas mais elevadas se caracterizam por um conjunto de cristas alongadas, alinhadas preferencialmente nas direções W - E e SW - NE. Apesar da forma alongada, estas cristas não são contínuas, sendo recorrentemente interrompidas por selas erosivas mais rebaixadas formadas pela erosão remontante das cabeceiras de drenagem. Esta orientação preferencial das morfologias nas direções W - E e SW - NE é resultado de um controle estrutural do embasamento. Ao longo de praticamente toda esta unidade, predominam as formas de topo convexas, com declividades suaves a intermediárias, características da exposição das rochas cristalinas ao clima subtropical úmido. Estes topos são recobertos por material intemperizado no próprio local (elúvios). Estes elúvios costumam ser pouco profundos, muitas vezes inferiores a $1 \mathrm{~m}$ de espessura. Algumas estruturas das rochas de origem (tais como diques e veios) permanecem preservados no interior do material já alterado, o que comprova que a intemperização destes materiais ocorre diretamente no local, sem indícios de que possam ter sido transportados.

Sobre alguns topos do relevo, é comum encontrar blocos de matacão, coesos, arredondados, emergindo do material alterado. Estes blocos surgem em locais onde a rocha matriz originalmente apresentava conjuntos de diáclases perpendiculares entre si. Quanto à predisposição à erosão, esta unidade é classificada como de média predisposição. Apesar das declividades serem relativamente suaves, o solo pouco espesso é um fator desfavorável, pois não permite uma grande infiltração da precipitação, favorecendo $o$ escoamento superficial e, consequentemente, os processos erosivos a este associados.

A transição para a unidade do Planalto Rebaixado Marginal se dá através de um aumento da declividade média e uma redução da altitude.

\subsubsection{Planalto Rebaixado Marginal}

O Planalto Rebaixado Marginal corresponde a uma porção mais dissecada da borda da região geomorfológica do Planalto SulRiograndense. Em relação à unidade dos Planaltos Residuais Canguçu - Caçapava do Sul, a unidade do Planalto Rebaixado Marginal representa um patamar em nível geral mais rebaixado.

Morfologicamente, o Planalto Rebaixado Marginal corresponde à toda área de transição entre os grandes divisores de águas das principais bacias hidrográficas do município (que pertencem à unidade dos Planaltos Residuais Canguçu - Caçapava do Sul) e os vales associados aos grandes eixos de drenagem. Fazem parte desta unidade as bordas de contato com a unidade mais elevada, mas também uma série de morros e colinas no interior destas bacias, com altitudes entre 50 e $150 \mathrm{~m}$, que se encontram no interior destas bacias hidrográficas. Em alguns casos, estes morros podem estar isolados no interior dos vales, tendo sido separados das áreas mais 
contínuas da mesma unidade em função da dissecação provocada rede hidrográfica.

Uma das características mais marcantes desta unidade está associada com a declividade e com a morfologia dos vales dos grandes eixos de drenagem. Os principais vales que cortam o município são alongados nas direções preferenciais W - E e SW - NE, e geralmente eles tendem a apresentar um perfil assimétrico, com vertentes mais elevadas e mais íngremes voltadas para o sul, e vertentes mais baixas e menos íngremes voltadas para o norte. No município de Arroio do Padre, no interior da unidade geomorfológica do Planalto Rebaixado Marginal, é possível observar que as maiores declividades estão voltadas para o quadrante sul, e as cristas do relevo se alongam seguindo o alinhamento preferencial das feições estruturais formadas pelas forças tectônicas compressivas. Como na unidade geomorfológica precedente, o Planalto Rebaixado Marginal está recoberto por material intemperizado eluvial, porém a espessura destes materiais inconsolidados tem forte relação com a declividade: nos setores de forte declividade, praticamente não há cobertura eluvial, estando a rocha matriz aflorando em superfície. Em razão das fortes declividades e dos solos pouco profundos, desfavoráveis à infiltração, a unidade geomorfológica do Planalto Rebaixado Marginal apresenta uma forte predisposição à erosão.

A transição para a unidade da Planície Alúvio-Coluvionar, inicia-se a formação de depósitos sedimentares de origem aluvial e coluvial. Esta transição é marcada por uma brusca redução na declividade e um espessamento na cobertura de material inconsolidado sobre a rocha matriz.

\subsubsection{Planície Alúvio-Coluvionar}

A unidade Planície Alúvio-Coluvionar corresponde as áreas mais baixas, inferiores a $50 \mathrm{~m}$ de altitude, das bacias do Arroio Pimenta e do Arroio do Padre. Por serem áreas receptoras de material sedimentar, estas áreas foram inseridas dentro da região geomorfológica da Planície Continental, e caracterizadas como modelados de acumulação de sedimentos.

Considerando algumas diferenças morfológicas e processuais, esta unidade foi subdividida em dois tipos de modelados distintos:

\section{a) Modelado de Acumulação Coluvial ou de Enxurrada}

Correspondem às áreas mais rebaixadas ou em bacia nos fundos de vale, onde ocorre a convergência de leques de espraiamento de origem coluvial oriundos das áreas mais elevadas do entorno ou a concentração de depósitos de enxurradas. Estas áreas ficam preenchidas por sedimentos de diferentes granulometrias, mas preferencialmente arenosos e lamosos quando o transporte e a deposição são realizados pelos agentes fluviais. No caso da ocorrência de grandes enxurradas, como a que atingiu o município em novembro de 2010, estas áreas podem ser completamente entulhadas por espessos depósitos sedimentares, estratificados e com granodecrescência ascendente, em razão da progressiva redução de energia após a passagem do pico de cheia

\section{b) Modelado de Acumulação em Planície Fluvial}

São aquelas áreas de acumulação de sedimentos construídas pela própria dinâmica fluvial, correspondendo às várzeas atuais, sujeitas a inundações periódicas. Caracterizam por serem superfícies planas ou levemente inclinadas, podendo ter suaves ondulações em sua superfície formadas pela passagem das águas durante as inundações. Como é o esperado para este tipo de depósito, alternam estratificações horizontais com camadas mais arenosas (depositadas durante as cheias) e camadas de material mais fino (que podem ser depositados ao final das cheias, quando os materiais de menor granulometria decantam na água parada). Em alguns setores, estas superfícies podem apresentar curtos segmentos de canais fluviais abandonados, parcial ou totalmente preenchidos por sedimentos e não muito distantes do canal atualmente ativo.

\subsection{Alterações Geomorfológicas}

A análise das fotografias cedidas pela Prefeitura Municipal de Arroio do Padre e pela EMATER permitiu ter uma melhor noção da dimensão do evento que atingiu o município em 15 de novembro de 2010. As imagens de 
satélite de alta resolução permitiram um comparativo entre o período anterior e posterior a ocorrência desta enxurrada.

A análise das fotografias cedidas, a interpretação das imagens de satélite e as observações de campo mostraram que a enxurrada atingiu quase que exclusivamente a bacia hidrográfica do Arroio Pimenta, na metade norte do município. Por este motivo, as etapas de levantamento das consequências da enxurrada e as entrevistas foram realizadas nesta bacia hidrográfica. Todas as consequências levantadas em campo foram sistematizadas no Mapa de Alterações Geomorfológicas da Bacia Hidrográfica do Arroio Pimenta (Fig.6).

Levando-se em consideração os aspectos geomorfológicos, as consequências da enxurrada de 15 de novembro de 2010 na bacia hidrográfica do Arroio Pimenta foram subdivididas em Alterações Geomorfológicas sobre as Vertentes e Alterações Geomorfológicas na Rede de Drenagem.

\subsubsection{Alterações Geomorfológicas sobre as Vertentes}

Foram observados sobre as vertentes da bacia hidrográfica do Arroio Pimenta a ocorrência de processos de erosão laminar e linear, movimentos de massa (escorregamentos e quedas de blocos). Todos estes processos foram desencadeados e/ou agravados pelo grande volume de precipitação em um curto período de tempo sobre as vertentes de elevada declividade desta bacia hidrográfica. Esta bacia concentra a maior parte das vertentes de forte declividade do município, com declividades superiores a 30 graus. Ainda neste local, a estrutura da rocha subjacente, muito foliada e fraturada em função da tectônica pretérita, mergulha na mesma direção do declive, o que aumenta o grau de instabilidade destas vertentes.

Outros fatores agravantes que também devem ser considerados são os tipos de solo e o uso e ocupação do solo nesta área, sendo que predominam solos rasos, do tipo Neosolo Litólico, com forte limitação à infiltração e altamente suscetível à erosão (OLIVEIRA, JACOMINE e CAMARGO, 1992; IBGE, 2003b; PMAP, 2008). Sobre estes solos, desenvolvemse atividades agrícolas tais como a fumicultura, com pouco ou nenhum manejo preventivo à erosão.

Nos locais de declividade mais acentuada, foi possível observar a presença de sulcos e ravinas, algumas delas cortando as lavouras de fumo (Fig.3A). Em algumas vertentes, ocorreram movimentos de massa, com danos a algumas moradias, o que obrigou os moradores destas áreas a abandonarem as suas residências (Fig.3C e Fig.3D).

O material sedimentar removido pela erosão foi transportado e depositado nas áreas de menor declividade (fundos de vale) quando a água começou a reduzir a sua energia (Fig.3B). 

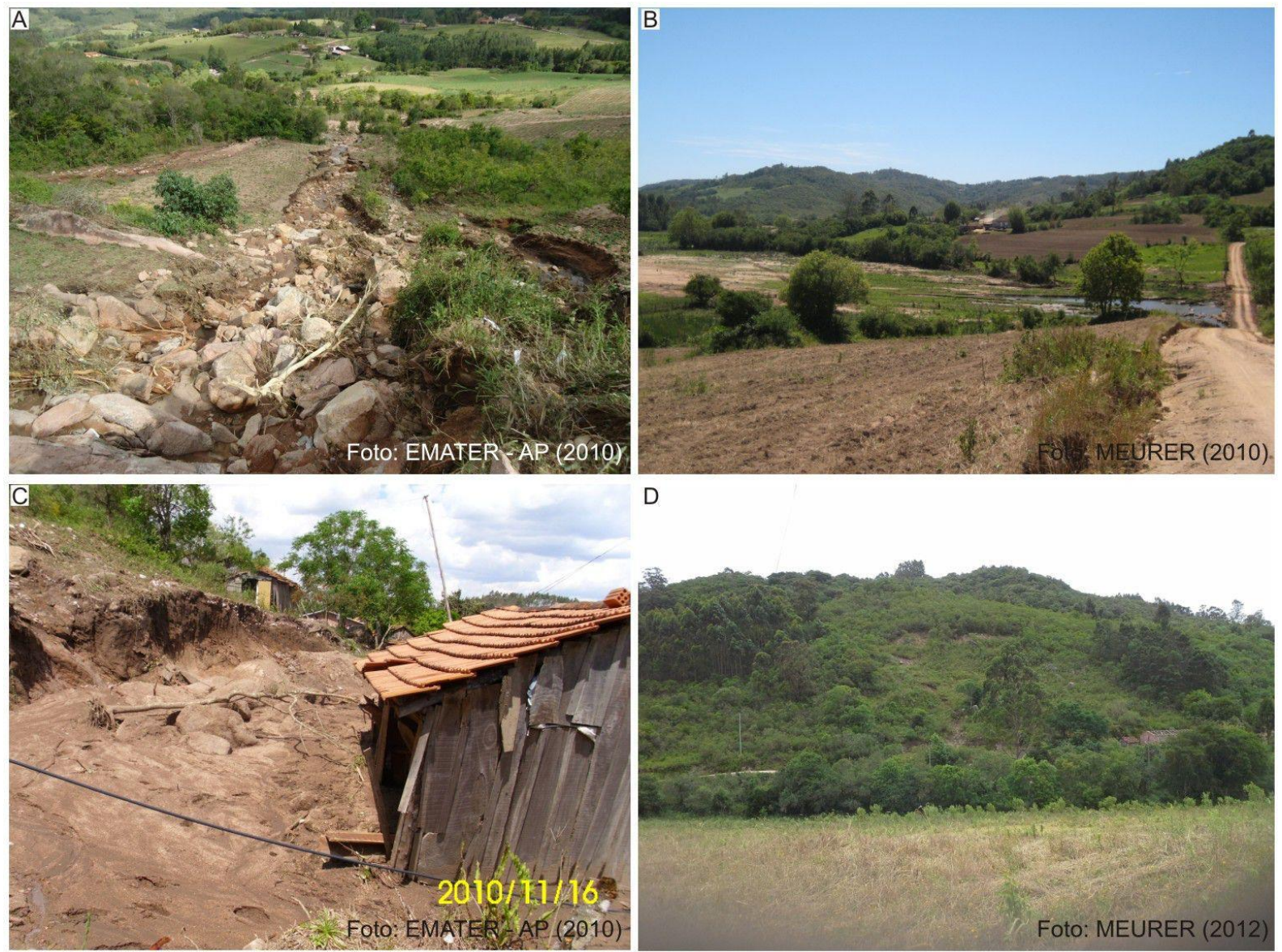

D

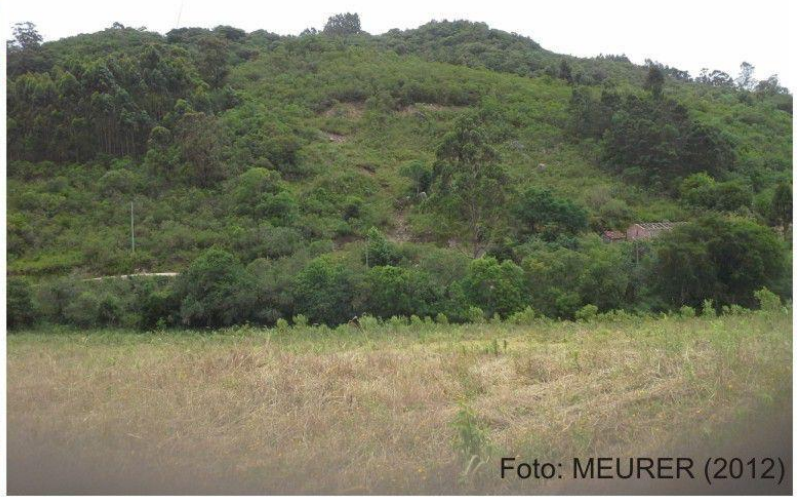

Figura 3. Alterações geomorfológicas sobre as vertentes. A) Forte erosão linear em área de lavoura, expondo os solos pouco profundos; B) Entulhamento do médio e baixo vale do Arroio Pimenta (à esquerda); C) Rolamento de blocos e fluxo de detritos que atingiu um galpão; D) Cicatriz de movimento de massa em vertente de forte declividade.

\subsubsection{Alterações Geomorfológicas sobre a Rede de Drenagem}

Foram observadas ao longo da rede hidrográfica da bacia do Arroio Pimenta uma série transformações tais como o alargamento do leito médio em função da erosão marginal, o rebaixamento do leito em alguns trechos de canal com e exumação do embasamento devido à forte incisão vertical, a mudança da posição do leito (avulsão fluvial), o barramento de um curso d'água provocado pelo imbricamento de blocos e matacões, e o entulhamento dos canais fluviais nos trechos de menor declividade pelos sedimentos oriundos dos setores a montante (Fig.4).

O alargamento do leito médio em função da erosão marginal é uma das consequências mais facilmente percebidas pelos moradores das áreas rurais de Arroio do Padre. Com a passagem da enxurrada, a ação mecânica da

água provoca o desgaste e o desprendimento do material das margens, resultando no alargamento do chamado leito médio. As margens ficaram visivelmente verticais, e a diferença de coloração nas rochas das margens e do fundo do canal permitem diferenciar os leitos pré e pós enxurrada.

Em muitos trechos a erosão de margens não ocorreu de forma isolada, mas em conjunto com um forte processo de incisão vertical, que provocou o rebaixamento do leito, em alguns locais provocando inclusive a exumação do embasamento subjacente. Em um dos afluentes do Arroio Pimenta, a incisão vertical fez com que um pequeno tributário intermitente ficasse suspenso em relação ao seu curso d'água receptor. Na confluência destes dois cursos d'água, formou-se um pequeno desnível, da ordem de $1 \mathrm{~m}$, entre este canal intermitente e o afluente do Arroio Pimenta. 
Em um dos setores de maiores transformações, foi possível identificar um processo de mudança de posição do leito do curso d'água (avulsão fluvial). Segundo Assine et al (2005) esse processo ocorre quando o canal muda de posição para locais que eram anteriormente fora do seu domínio. No caso observado em campo, um dos afluentes do
Arroio Pimenta abandonou um trecho em curva acentuada, escalonado, de forte declividade, e escavou um novo canal mais retilíneo, estreito, com uma única queda d'água. A jusante desta queda d'água, a incisão vertical deu origem a um canal estreito, de margens íngremes, e fundo rochoso.
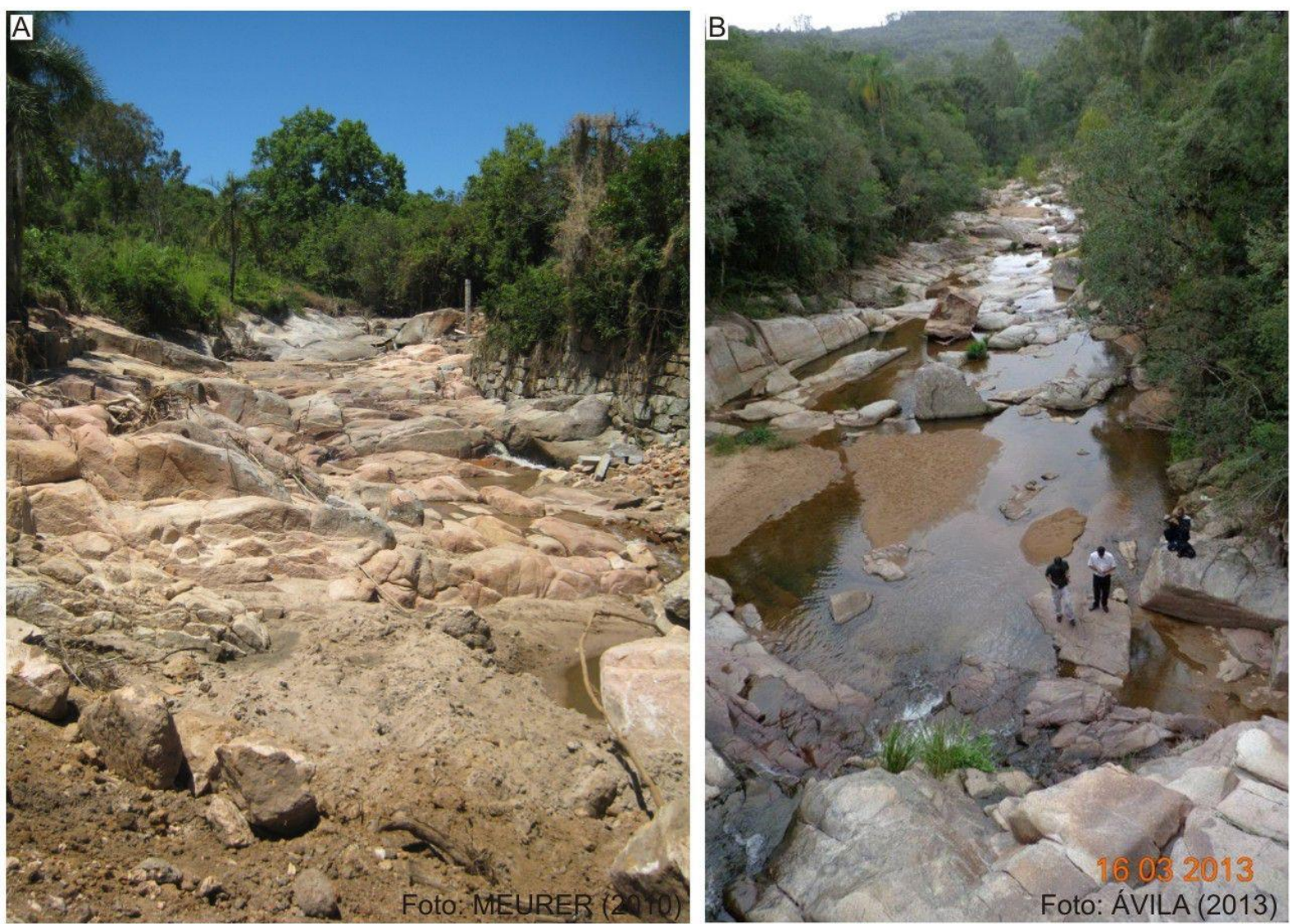

C

。

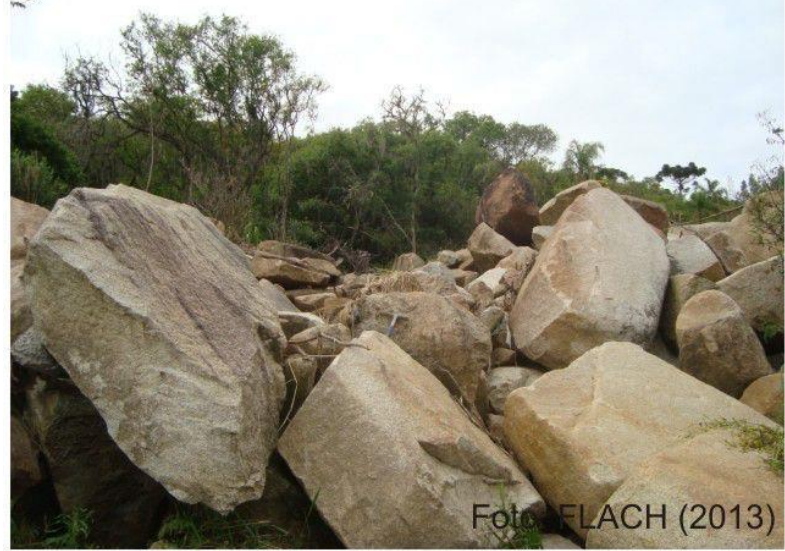

Foto: ÁVILA (2013)

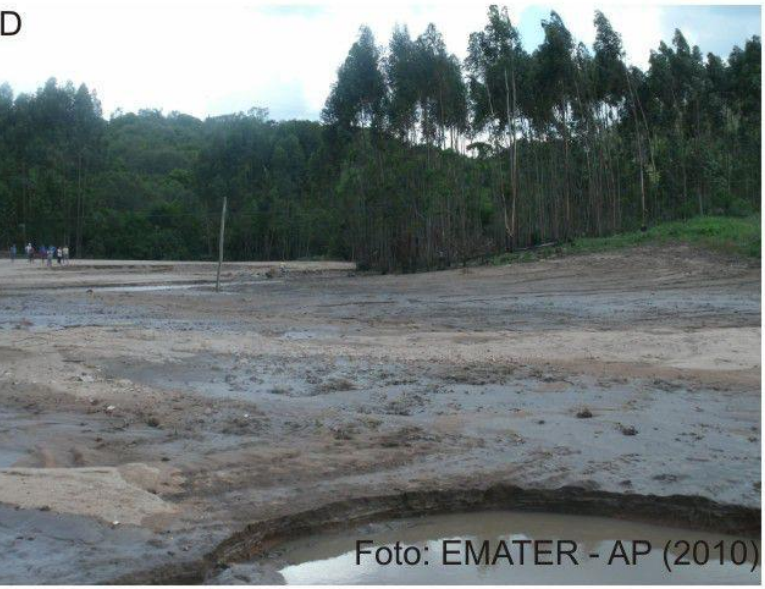

Figura 4. Alterações geomorfológicas ao longo da rede de drenagem. A) Exaustão de sedimentos, com exposição do bed-rock; B) Alargamento do canal fluvial; C) Deposição de matacões imbricados, resultante do intenso fluxo da enxurrada; D) Entulhamento do fundo de vale com materiais arenosos e lamosos. 
Em virtude da forte erosão nos trechos de maior declividade, uma quantidade considerável de sedimentos das mais diferentes granulometrias foi remobilizada e depositada nos trechos de canal com menor declividade. Em um dos trechos mais marcantes onde este processo de deposição foi observado, blocos e matacões oriundos das áreas de maior declividade a jusante rolaram pelo leito do curso d'água e se depositaram de maneira imbricada em um segmento de menor declividade. A deposição destes blocos provocou um barramento do segmento a montante, dando origem a um pequeno lago parcialmente preenchido pela deposição dos materiais mais finos (grânulos, areias, silte e argila).

Nos fundos de vale de declividade mais reduzida, houve intensa deposição de materiais arenosos e lamosos. Este foi o caso de um vale amplo e de reduzida pendente que se encontra no terço intermediário da bacia do Arroio Pimenta, circundado por vertentes de forte declividade. Após a enxurrada, este local ficou conhecido pelos moradores como "prainha", em virtude do entulhamento provocado pela quantidade de material sedimentar arenoso e lamoso, que modificou completamente a morfologia deste segmento da rede de drenagem. Em alguns setores dos arroios a acumulação de sedimentos foi bastante eficiente, tornando os canais mais rasos e/ou elevando ligeiramente o fundo do leito. Nas porções mais distais da bacia, os sedimentos recebidos foram estocados sobre as áreas de planície fluvial.

\subsubsection{A Percepção dos Moradores e as Práticas de Manejo da Propriedade}

As entrevistas sob percepção dos moradores sobre a enxurrada 15 de novembro de 2010 foram realizadas com 9 famílias residentes na bacia hidrográfica do Arroio Pimenta. Para obter informações sobre a totalidade da bacia, foram selecionados aleatoriamente domicílios nas partes superior, intermediária e inferior da bacia. Foi dada preferência para as residências localizadas próximas aos cursos d'água por considerar que as pessoas residentes nestas áreas provavelmente observaram de maneira mais próxima a ocorrência da enxurrada.
Questionados quanto à origem da enxurrada, alguns moradores afirmaram acreditar que o evento é de origem natural, entretanto, grande parte dos entrevistados não soube precisar qual poderia seria a origem da enxurrada. Os entrevistados relataram também que nunca antes haviam vivenciado um evento semelhante, só tendo visto algo deste tipo apenas pela televisão, ou então só tendo presenciado enchentes menores.

Com relação a possibilidade da sua propriedade estar em uma área de risco, apenas dois entrevistados responderam de forma positiva, que estão em área de risco: um devido a proximidade com o arroio e outro devido ao deslizamento de terra e rochas. Em alguns momentos das entrevistas foi possível observar uma certa contradição de ideias nas respostas fornecidas. Alguns entrevistados não consideraram que a sua propriedade estivesse em área de risco, salvo no caso de ocorrência de muita chuva, ou no caso da vinda de lama de outros lugares afetando as pastagens. Outros não consideraram que a propriedade estivesse em área de risco, argumentando que "a propriedade não está tão próxima do morro", ou porque "deixam a vegetação crescer para segurar o solo".

Em um momento da pesquisa, os entrevistados foram questionados quanto às técnicas adotadas na prevenção à erosão. Apenas dois entrevistados afirmaram não adotar nenhuma técnica preventiva. Os demais entrevistados citaram o uso de técnicas tais como o plantio em curvas de nível, o plantio direto, a construção de muros de pedra e o plantio de árvores. Quando questionados se poderiam fazer mais alguma coisa, alguns acreditam que sim, mas com o auxílio técnico da EMATER. Dentre as práticas citadas neste caso estão a construção de barreiras (de pedra), deixar crescer a vegetação e plantar pasto.

Durante a fase das observações de campo e das entrevistas foi possível identificar que muitas áreas de agricultura com declividades acentuadas foram atingidas por processos de erosão laminar e linear, sendo removidas grandes quantidades de material sedimentar. Esse material sedimentar acabou sendo depositado em áreas de agricultura com declividades mais suaves. Em suma, o material removido das áreas com declividades mais 
acentuadas foi um dos responsáveis pelos estragos nas lavouras e pastagens em terrenos mais suaves.

Em conversa com os técnicos da Prefeitura Municipal de Arroio do Padre e da EMATER, os referidos técnicos afirmaram que, apesar do trabalho de conscientização que é constantemente realizado, muitas propriedades não utilizam técnicas de controle à erosão, e em muitas propriedades são utilizadas técnicas de preparo da terra incompatíveis com a fragilidade dos solos (tais como o uso de arado e subsolador em locais não recomendados para este tipo de manejo). Isso traz como consequência, uma intensificação dos processos erosivos e possivelmente uma grande perda de solo durante os momentos de maior precipitação.

\section{Conclusões}

A enxurrada que atingiu o município de Arroio do Padre em 15 de novembro de 2010 teve como causa principal o grande volume de precipitação em um curto intervalo de tempo, entretanto, outros fatores contribuíram para que este evento se configurasse como um desastre natural e provocasse as alterações geomorfológicas repertoriadas nesta pesquisa.

A declividade foi um dos fatores mais importantes para se entender as causas da enxurrada e a distribuição espacial das suas consequências. Através dos mapas hipsométrico e de declividades elaborados na etapa de mapeamento geomorfológico foi possível observar que o município de Arroio do Padre concentra muitas áreas de forte declividade, em especial na metade norte do município. Em razão da assimetria de alguns vales, consequente do comportamento estrutural do relevo no município, muitas destas áreas de forte declividade estão situadas nas vertentes voltadas para o Sul e Sudeste, fazendo a ligação entre os topos das áreas mais elevadas e os fundos de vale dos principais cursos d'água do município. De acordo com (GUHA - SAPIR et al, 2012), nos setores de forte declividade a água flui rapidamente para a rede de drenagem, e com potencial destrutivo bastante expressivo. O que foi verificado em Arroio do Padre foi exatamente isto: a concentração de processos erosivos e movimentos de massa nos setores de forte declividade, e a ocorrência de processos deposicionais (entulhamento) nas áreas onde esta declividade se reduz.

Outro fator importante a ser considerado para o entendimento da ocorrência desta enxurrada são as características dos solos no município. Nesta área, predominam solos dos tipos Neossolo Litólico e Argissolo Vermelho Amarelo. O primeiro caracteriza-se por ser um solo extremamente raso, sobreposto diretamente sobre a rocha sã; o segundo caracteriza-se como um solo um pouco mais profundo, mas com a ocorrência de um horizonte $\mathrm{B}$ textural muito próximo da superfície. Em função destas características, ambos solos têm limitações quanto à capacidade de infiltração. Durante o evento de 15 de novembro de 2010, ocorreu uma rápida saturação desses solos, o que aumentou o volume do escoamento superficial. $\mathrm{O}$ aumento do escoamento superficial associado às fortes declividades foi determinante para a ocorrência da enxurrada, pois a água precipitada chegou mais rápida e com maior energia à rede de drenagem, provocando um rápido aumento no pico de vazão. Por se tratarem de bacias hidrográficas de pequena área, as consequências de um episódio de precipitação concentrada facilmente recobrem toda a área da bacia, e as respostas hidrológicas tendem a ser rápidas e intensas, independentemente da morfometria destas bacias ser ou não favorável à ocorrência de enxurradas. Flach e Meurer (2013) e Flach (2014) já haviam estudado a morfometria da Bacia Hidrográfica do Arroio Pimenta, e mostrado que, com exceção da área, os demais parâmetros morfométricos desta bacia não poderiam explicar a ocorrência da enxurrada. Agora sabe-se que outros fatores foram importantes para que o evento se desencadeasse da forma como ocorreu.

O Mapeamento Geomorfológico trouxe contribuições importantes para o entendimento das características do relevo do município, com o detalhamento de algumas unidades geomorfológicas, a inclusão e a exclusão de outras, bem como o detalhamento de alguns processos morfogenéticos. Através deste mapeamento, observou-se que as vertentes de elevadas declividades situadas na transição da unidade geomorfológica Planaltos Residuais Canguçu - Caçapava do Sul para a unidade 
geomorfológica Planalto Rebaixado Marginal foram as principais áreas de desencadeamento de processos morfogenéticos (erosão e movimentos de massa). Nos setores de redução de declividade, na transição entre a unidade Planalto Rebaixado Marginal e a Planície Alúvio-Coluvionar, bem como em algumas áreas de menor declividade na unidade Planalto Rebaixado Marginal, os processos de deposição (entulhamento) foram bastante significativos.

O mapa elaborado não dá por encerrada a pesquisa geomorfológica no município, mas abre caminhos para um detalhamento do mesmo (avançando para a delimitação dos padrões de formas de relevo e para um detalhamento dos processos).

Tanto o mapa geomorfológico como o mapeamento das consequências da enxurrada mostraram que existem setores preferenciais de maior risco à ocorrência de processos erosivos, de movimentos de massa, de inundação e de processos deposicionais. Isto abre caminho para um futuro trabalho de mapeamento de risco em Arroio do Padre, onde sejam tratadas questões como a predisposição e a vulnerabilidade aos eventos extremos.

Por fim, esta pesquisa reforça o que os técnicos da administração municipal e da EMATER já observaram: a necessidade de organizar programas de medidas preventivas e corretivas relacionadas aos processos erosivos, principalmente nas áreas de agricultura em terrenos de forte declividade. 


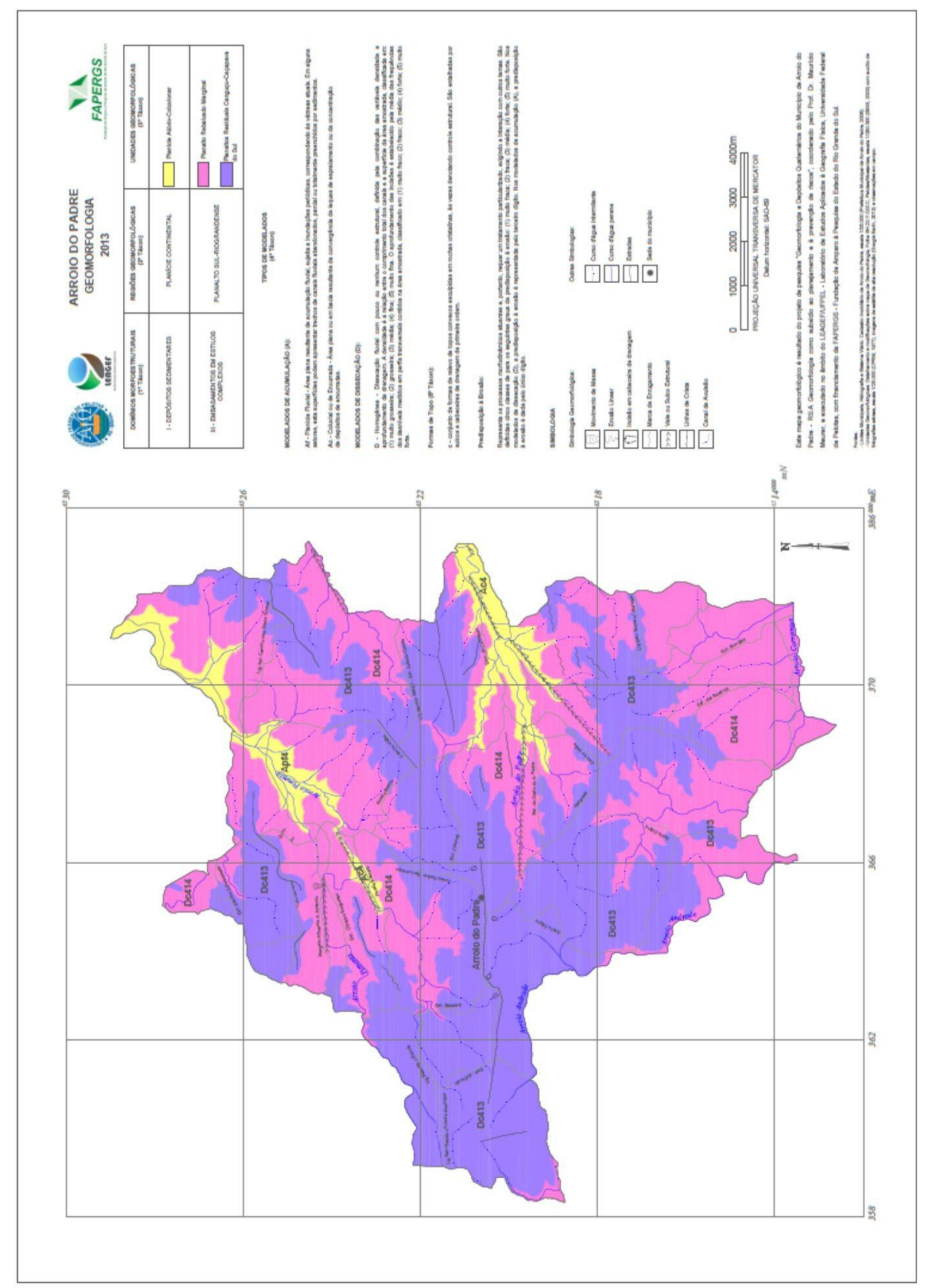

Figura 5. Mapa Geomorfológico do Município de Arroio do Padre - RS. 


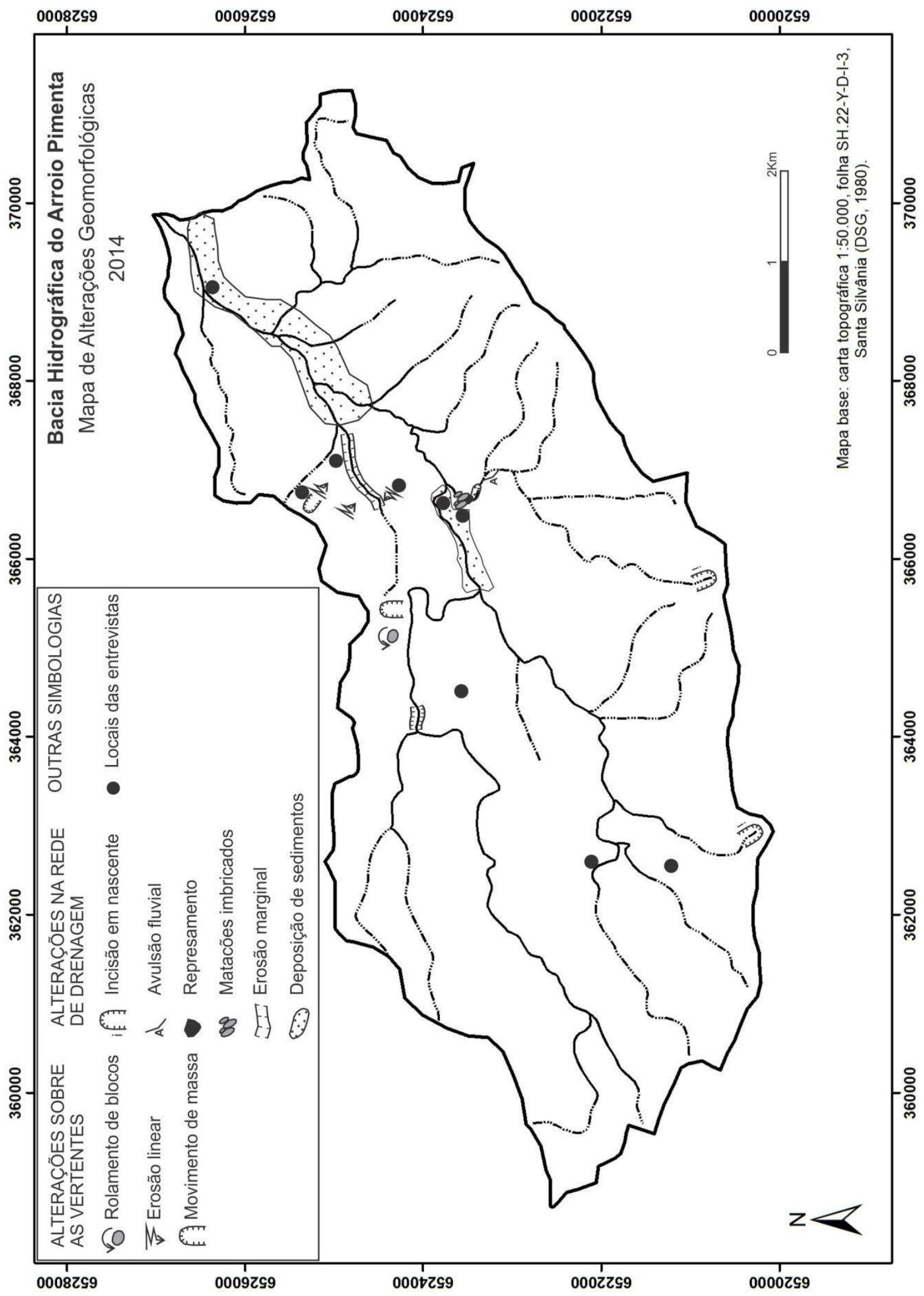

Figura 6. Mapa das alterações Geomorfológicas na Bacia Hidrográfica do Arroio Pimenta 


\section{Agradecimentos}

Os autores agradecem à Fundação de Amparo à Pesquisa do Estado do Rio Grande do Sul pelo financiamento do projeto "Geomorfologia e Depósitos Quaternários do Município de Arroio do Padre - RS: A Geomorfologia como subsídio ao planejamento e à prevenção de riscos", através do Edital 01/2011 - ARD, e à Prefeitura Municipal de Arroio do Padre pelos materiais cedidos para a realização desta pesquisa.

\section{Referências}

Assine, M.L.; Padovani, C.R.; Zacharias, A.A.; Angulo, R.J.; Souza, M.C.de. Compartimentação geomorfológica, processos de avulsão fluvial e mudanças de curso do Rio Taquari, Pantanal Mato-Grossense. Revista Brasileira de Geomorfologia, ano 6, n.1. p. 97108, 2005.

Brasil. Ministério das Minas e Energia. Projeto RADAMBRASIL: levantamento dos recursos naturais. Folha Pelotas/Mostardas, SH-22-Y-D, 1:250.000, 2003.

Casseti, V.; Nascimento, M. A. L. S. A importância da geomorfologia nos estudos de risco urbano: o caso de Goiânia. Anais do IV Simpósio de Geografia Física Aplicada, Porto Alegre, p. 374-81, 1991.

CPRM. Carta Geológica. Programa Levantamentos Geológicos Básicos do Brasil. Folha Pelotas, SH-22-Y-D, 1:250.000, 2000.

Dias, T. S.; Fujimoto, N. S. V. M. ; Soares, A. Q. Compartimentos de Relevo do Município de Porto Alegre - RS. In: Anais do XIII Simpósio Brasileiro de Geografia Física Aplicada, 2009, Viçosa - MG. A Geografia Física Aplicada e as Dinâmicas de Apropriação da Natureza. Viçosa - MG : Universidade Federal de Viçosa, 2009.

EMATER. Laudo preliminar de Prejuízos Econômicos na atividade Agropecuária do Município em decorrência do Excesso de Chuvas e Granizo. Arroio do Padre: EMATER, 2010.

Flach, C. W. Alterações geomorfológicas decorrentes da enxurrada de 15 de novembro de 2010 na Bacia Hidrográfica do Arroio Pimenta, no município de Arroio do Padre/RS. Trabalho de conclusão, 2014.

Flach, C. W.; Meurer, M. Análise Morfométrica da Bacia do Arroio Pimenta - Arroio do Padre/RS. Anais do XXII Congresso de Iniciação Científica da Universidade Federal de Pelotas, 2013.

Guha-Sapir, D.; Vos, F.; Below, R.; Ponserre, S. Annual Disaster Statistical Review 2011 - The numbers and trends. Centre for Research on the Epidemiology of Disasters (CRED) Institute of Health and Society (IRSS) Université Catholique de Louvain - Brussels, Belgium, 2012.

Hasenack, H.; Weber, E. (Org.). Base cartográfica vetorial contínua do Rio Grande do Sul - escala 1:50.000. Porto Alegre: UFRS-IBCentro de Ecologia, 2010. 1DVD.

Instituto Brasileiro de Geografia e Estatística. Projeto RADAMBRASIL: Levantamento dos recursos naturais. v. 33. Rio de Janeiro, 796p., 1986.

Instituto Brasileiro de Geografia e Estatística. Geomorfologia. 1 mapa. Escala: 1:250.000. Folha SH-22-Y-D, Pelotas, 2003a.

Instituto Brasileiro de Geografia e Estatística. Solos. 1 mapa. Escala: 1:250.000. Folha SH-22-YD, Pelotas, $2003 \mathrm{~b}$.

Instituto Brasileiro de Geografia e Estatística. Manual técnico de Geomorfologia. 2a . ed. - Rio de Janeiro: IBGE. 182 p., 2009.

Instituto Brasileiro de Geografia e Estatística. Primeiros Resultados do Censo 2010. Base de Dados Cidades. Disponível em: [http://www.ibge.gov.br/cidadesat/topwindow .htm?1]. Acesso: 2013.

Kobyiama, M.; Mendonça, M.; Moreno, D.A.; Marcelino, I.P.V.de O.; Marcelino, E.V.; Gonçalves, E.F.; Brazetti, L.L.P.; Goerl, R.F.; Molleri, G.S.F.; Rudorff, F. de M. Prevenção de Desastres Naturais: conceitos básicos. Curitiba: Ed. Organic Trading, 2006. 
Lambert, R. Géographie du Cycle de l'Eau, Toulouse: Presses Universitaires du Mirail, 1996.

Menezes, D.J.; Sccoti, A.A.V. Inventário de registro de inundações no Estado do Rio Grande do Sul entre 1980 e 2010. In: Robaina, L.E.deS.; Trentin, R. Desastres Naturais no Rio Grande do Sul. Santa Maria: Ed. UFSM, 2013.

Meurer, M. Geomorfologia e Depósitos Quaternários do município de Arroio do Padre - RS: A geomorfologia como subsídio ao planejamento e à prevenção de riscos. Relatório de Pesquisa apresentado à FAPERGS referente ao Edital 01/2011 - ARD, 2013.

Oliveira, J.B.de; Jacomine, P. K. T.; Camargo, M. $\mathrm{N}$. Classes gerais de solos do Brasil: guia auxiliar para seu reconhecimento. 2.ed. Jaboticabal: FUNEP, 1992.

PMAP. Prefeitura Municipal de Arroio do Padre. Plano Ambiental Municipal de Arroio do Padre, RS. Arroio do Padre, RS, 2008, 74 p.

Robaina, L. E.deS.; Oliveira, E. L. de A. Bases conceituais para o estudo de áreas de risco em ambientes urbanos. In: Robaina, L.E.deS.; Trentin, R. Desastres Naturais no Rio Grande do Sul. Santa Maria: Ed. UFSM, 2013.

Ross, J. L. S. Registro cartográfico dos fatos geomorfológicos e a questão da taxonomia do relevo. Revista do Departamento de Geografia. 17-29 pp. São Paulo, IG-USP, 1992.

Santos, C. A.; Sobreira, F. G. Cartografia Geomorfológica como Subsídio ao Ordenamento Territorial das Bacias do Ribeirão Carioca, Córrego do Bação e Córrego Carioca, Itabirito, MG. Simpósio Nacional de Geomorfologia, 6. CD Anais... Goiânia-GO: UGB, 2006.

Sausen, T. M.; Lacruz, M. S. P.; Saito, S. M.; Pereira, R. da S. Análise do Evento de Inundação Brusca ocorrido em São Lourenço do Sul, RS, em 10 de março de 2011. INPE: São José dos Campos, 2012.

Tagliani, C. R. A. A mineração na porção média da Planície Costeira do Rio Grande do Sul: estratégia para a gestão sob um enfoque de Gerenciamento Costeiro Integrado. 2002. Porto
Alegre, RS. Tese de Doutorado - Instituto de Geociências, Programa de Pós-graduação em Geociências, Universidade Federal do Rio Grande do Sul, Porto Alegre, 2002. 252 p.

Tominaga, L. K. Desastres Naturais: Por que ocorrem? In: Tominaga, L.K.; Santoro, J.; Amaral, R. do A. (orgs). Desastres Naturais: conhecer para prevenir. São Paulo: Instituto Geológico - 2009. 